\title{
Aportes teóricos para la conceptualización de los espacios de representación de Henri Lefebvre
}

\section{Theoretical contributions for the conceptualization of Henri Lefebvre's spaces of representation}

\author{
Enrique de Jesús Castro-Martínez ${ }^{1}$ \\ Universidad Nacional Autónoma de México, México
}

\begin{abstract}
Resumen
Los espacios de representación comprenden a una dimensión de la teoría unitaria de la producción del espacio propuesta por Henri Lefebvre, se apela a que en esta dimensión espacial responde a múltiples interpretaciones debido a su carácter polivalente y polisémico. Por tal motivo, proponemos tres explicaciones que obedecen al símbolo como una interpretación de los espacios de representación: primero se sitúa los símbolos naturales que posteriormente el ejercicio del poder de la religión y las fuerzas políticas se han apropiado; segundo responde al advenimiento de la modernidad que los símbolos de la vida cotidiana son dominados por la técnica y por el ascenso del capitalismo; y, el tercero corresponde al contra-espacio que promueve la resistencia urbana que dotará la recuperación de colectividades producidas por el habitar.
\end{abstract}

Palabras clave: Espacios de representación, Henri Lefebvre, símbolos, espacio y contra-espacio.

\begin{abstract}
Spaces of representation comprise a dimension of the unitary theory of the production of space proposed by Henri Lefebvre and responds to multiple interpretations in view of its polyvalent and polysemic character. For this reason, we propose three explanations that cast symbols as interpretations
\end{abstract}

1 Licenciado y Maestro en Geografía por la Universidad Nacional Autónoma de México, correo electrónico: quiquecasmar88@outlook.es. Producto derivado del proyecto del Programa de Apoyos a la Investigación e Innovación Tecnológica. PAPIIT IN302120. "Financiarización del mercado inmobiliario: nuevas formas, actores y escalas en la producción del entorno construido en la ciudad contemporánea". (D) https://orcid.org/0000-0001-5347-2085 
of the spaces of representation. First in mention are natural symbols which were subsequently appropriated by the exercise of power, religion and political forces; second, everyday life symbols, which respond to the advent of modernity, dominated by technique and the rise of capitalism; and thirdly, counter-space, which promotes urban resistance to provide the recovery of collectivities produced by living spaces.

Keywords: Representation spaces; Henri Lefebvre; Symbols; Space and counter-space.

\section{Introducción}

En los últimos años han aparecido una gran cantidad de documentos que tienen que ver con el pensamiento de Henri Lefebvre, en ocasiones ávidas de escisión por el desconocimiento triple de sus postulados tanto teóricos y empíricos. Aprovechando estos fallos condesamos algunas especificidades del pensamiento de Henri Lefebvre que son imprescindibles: primero el epígrafe del contra ante los planteamientos dogmáticos, a la reducción de postulados teóricos y conceptuales en las investigaciones, a la fragmentación del conocimiento extraído de los métodos enraizados por la cientificidad, pero sobre todo a su negatividad de los determinismos económicos, políticos y espaciales entre otros más.

Siguiendo el hilo, los espacios de representación no son ajenos a la evocación anterior, cada disciplina y enfoque teórico que responde a cada lector promoverá nuevas posibilidades interpretativas a los planteamientos de Lefebvre, pieza importante del método de transducción del ir más allá estimulando matices con múltiples tonalidades conceptuales. Así pues, los espacios de representación promueven un amplio abanico de exegesis pudiéndose considerarse desde las imágenes, el ritmo-análisis, los signos, las señales, la pintura, el arte, la literatura e inclusive el derecho a la ciudad entre otras categorías más.

Por tal motivo, el objetivo central de la presente investigación es analizar la dimensión espacial de los espacios de representación bajo la interpretación de los símbolos que propone Henri Lefebvre para contribuir en un sustento teórico para su correspondiente conceptualización. Para lograr dicho fin se pone énfasis al método cualitativo para alcanzar el objetivo antes propuesto.

Por ello, el soporte teórico se fundamenta por la revisión bibliográfica de algunas publicaciones de la obra literaria de Henri Lefebvre, esto permitirá conocer las múltiples interpretaciones que tocan a los espacios 
de representación para después proponer tres posibles conceptualizaciones donde la cuestión del símbolo corresponde a una posible interpretación.

Finalmente, el siguiente escrito se organiza de la siguiente manera: el primero se realiza una descripción de la formación pedagógica que de luz sobre el sustento teórico de los espacios de representación de Henri Lefebvre; el segundo apartado se sitúa en conceptualizar a los espacios de representación como una dimensión de la teoría unitaria de la producción del espacio; el tercer punto y más extenso se sitúa en conceptualizar bajo tres modalidades a los espacios de representación, los cuales corresponden a los espacios simbolizados, simbolización del capital en la vida cotidiana y el contra-espacio.

\section{Los espacios de representación: educación pedagógica e influen- cias en Henri Lefebvre}

Un tema central para conocer la influencia del pensamiento de Henri Lefebvre es escudriñar los primeros trabajos que realizaría mediante las traducciones del alemán al francés de los documentos marxistas o la influencia que obtuvo desde el desarrollo pedagógico de la filosofía cristiana que cimentarían a los espacios de representación.

A esto mismo, el aparato epistemológico de Lefebvre tendría como punto de partida los escritos de Nietzsche, que es donde proviene la propuesta de los espacios de representación en términos espaciales (espacio como producción social) o en términos de lo vivido (individual). Al respecto, Lefebvre menciona lo siguiente: "el autor (ego) enseña filosofía, lee y relee, primeramente. Nietzsche y, siempre (y con él es el combate, luego la adolescencia, la lucha con el ángel y el demonio), Marx y Hegel” (Lefebvre, 1976a, p. 5).

Otro tema importante fue el asesoramiento que obtuvo de su profesor Maurice Blondel que le acercaría a los escritos del libro X de Las Confesiones de San Agustín, al respecto de la educación filosófica de Lefebvre escribe lo siguiente:

Recuerdo con toda claridad esta paradójica iniciación a la filosofía que no ha podido menos que marcarme. La teoría del tiempo en San Agustín me asombraba y me atraía. En ella, el tiempo subjetivo y relativo se dilata, se dispersa o por el contrario se condensa tendiendo así hacia el momento 
eterno. La ambigüedad de lo vivido se revelaba en este texto de Las Confesiones que me atraían y horrorizaban a la vez (Lefebvre, 1976b, p. 21).

En otro ángulo de explicación que asocia a la idea anterior es la formación educativa de Lefebvre bajo el asesoramiento "con Blondel decía, he estudiado San Agustín y el agustinismo; más tarde descubrí a Jansenio, Pascal y el jansenismo del siglo XVII" (Lefebvre, 1976b, p. 25), pero, por cuenta propia: "él lee a Nietzsche y Spinoza a los quince años" (Hess y Weigand, 2006, p. 1) después estudió “[...] a los 22 años, en versión original y en latín, algunos textos de Joaquim de Fiore" (Lencioni, 2015, p. 65), este último tendría dos influencias en Lefebvre, una de ellas es la cuestión triádica, y la segunda es la cuestión iconográfica, a propósito una de las propuestas del Abad Joaquim de Fiore es su tabla XIb de su manuscrito del Libro de las Figuras simbolizadas en tres círculos la "Santísima trinidad". Tomando como ejemplo otro escrito por Fiore, en particular el Expositio in Apocalypsin que discute sobre el tema del tiempo, Lefebvre menciona lo siguiente:

El tiempo explicita y despliega la eternidad. La reproduce, pero separando lo que se distingue en el Eterno, a saber, las Tres (personas). De donde resultan tres periodos en el tiempo que reproducen analógicamente los atributos de las personas de la Trinidad: la Ley, que corresponde al Padre; la Fe, que corresponde al Hijo; el Júbilo, que corresponde al Espíritu (Lefebvre, 2006, p. 138).

De las postulaciones anteriores podemos mencionar que los espacios de representación tienen cierta influencia de filósofos y teólogos que después aterrizaría por los planteamientos promovidos por los pensadores del socialismo utópico representado por Saint-Simón, "el proyecto fourierista de la Ciudad" (Lefebvre, 1980a, p. 16), las arquitecturas simbolizadas funcionalistas modernas por Le Corbusier o "el pensamiento simbólico" (Lefebvre, 1980b, p. 150). A esta línea de redacción se inserta su paso por El Existencialismo (1984a) lo muestra bajo la rúbrica del siguiente subapartado: "POR QUE FUI EXISTENCIALISTA (1925) Y COMO ME HICE MARXISTA", aunque: "he escrito quizá sin la suficiente fuerza, que el existencialismo no era más que un avatar del marxismo" (Lefebvre, 1976b, p. 143). 
Bajo en este pensamiento de los espacios de representación existen textos que podrían tener cierta base interpretativa en común ${ }^{2}$, a esto, una de sus primeras publicaciones sería Nietzsche en 1939, a esta equivaldría sobre el tema de lo vivido, después comenzaría su trilogía de la Crítica de la vida moderna, que iniciaría el primer volumen en 1947, el segundo lo terminaría en el año de 1962, y, el último saldría a la luz en 1981, estas tres publicaciones tiene como tema central la incorporación del capital en la vida cotidiana donde los espacios de representación no son ajenos a esta problemática (Lefebvre, 2006, p. 224), un tema central en cuanto se reconoce que el Derecho a la Ciudad es conceptualizado desde los espacios de representación aparece un referente del contra-espacio a través de la publicación titulada: "La proclamación de la comuna" en 1965 y, un alusivo sustancial es La producción del espacio publicado en $1974^{3}$ donde se propone la trialéctica de la espacialidad (práctica del espacio, representación del espacio y los espacios de representación). Véase la figura 1.

Un ejercicio semántico de los 72 libros escritos por Henri Lefebvre durante la temporalidad de 1934 a 2018, registra un total de 204 palabras, en primer plano aparece el termino de Marx con 8 nombramientos, después con 6 menciones el Estado y con 4 aparecen las palabras: dialéctica, cotidiano, introducción, pensamiento, vida, Karl y Hegel.

Véase la figura 2. A esto mismo, lo que se puede observar es el dominio de la práctica espacial en la agenda de Henri Lefebvre, después el interés central sobre el Estado con los aportes de Hegel que equivaldría a la representación del espacio y, lo cotidiano que sería la contribución de los espacios de representación bajo el dominio del capital y el Estado, aunque consideramos que es desde esta dimensión espacial donde se realiza el contra-espacio que promueve el pensamiento dialéctico.

Es importante mencionar la contabilidad que se registró de la palabra introducción con 4, esto mismo expresa el interés de Lefebvre de producir

2 El acervo de Henri Lefebvre tiene magnitudes considerables, algunos textos todavía no han sido traducidos al español e inclusive al inglés, aunque en el peor de los casos es difícil de conseguir algunos de sus ejemplares. Sin embargo, creemos oportuno que algunos de sus escritos tienen influencias de manera directa o indirecta con los espacios de representación, por ejemplo: La conscience mystifiée; Contribution à l'esthétique; Rabelais; Musset; Pignon; Trois textes pour le théâtre, por mencionar algunos.

3 Es importante mencionar que solo es una alternativa de guía bajo el tema de los espacios de representación, por tal motivo, no caemos sobre el tema del determinismo, ya que pueden aparecer otras publicaciones que incorporen a los espacios de representación, como es: Position: contre les technocrates donde se menciona el dominio de la técnica en lo cotidiano o el ritmo-análisis (2007), por ejemplo. 
Figura 1. Posibles interpretaciones de publicaciones bajo la rúbrica de los espacios de representación

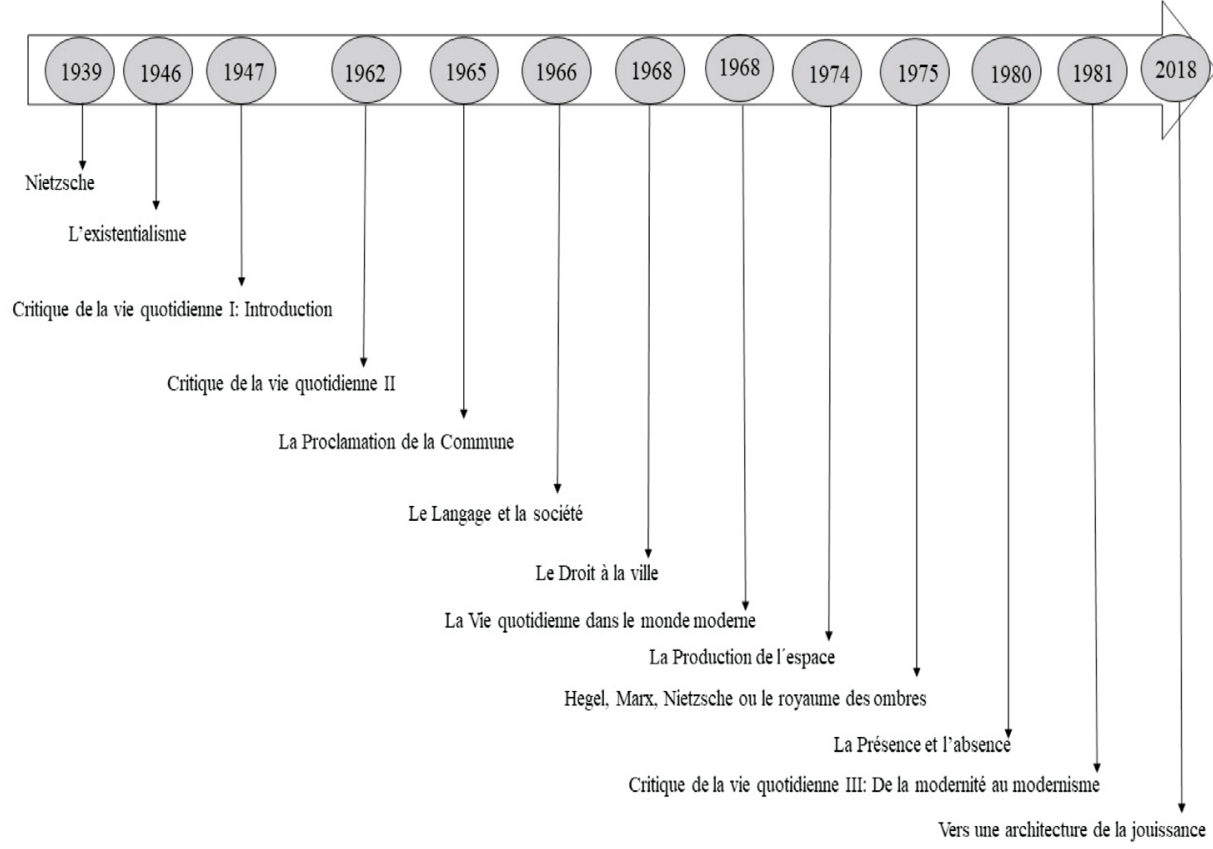

Fuente: Elaboración propia con base a la cronología de Martínez (2012, pp.11-12) y Lefebvre (2018, p. 49)

marcos teóricos sobre los temas que analiza donde el método regresivoprogresivo tiene un papel protagónico.

\section{Los espacios de representación una dimensión espacial de la teo- ría unitaria de la producción del espacio}

Una de las problemáticas que formula Henri Lefebvre reviste el interés central por la parcelación del conocimiento, al respecto, apunta lo siguiente:

Las investigaciones acaban en meras descripciones, que en ningún momento llegan a alcanzar el estatus analítico mucho menos el teórico, o terminan en fragmentos y secciones del espacio. Hay muchas razones que 
Figura 2. Principales palabras en las publicaciones de Henri Lefebvre, 1934-2018 se incluyó en el apartado "Los espacios de representación una dimensión espacial de la teoría unitaria de la producción del espacio"

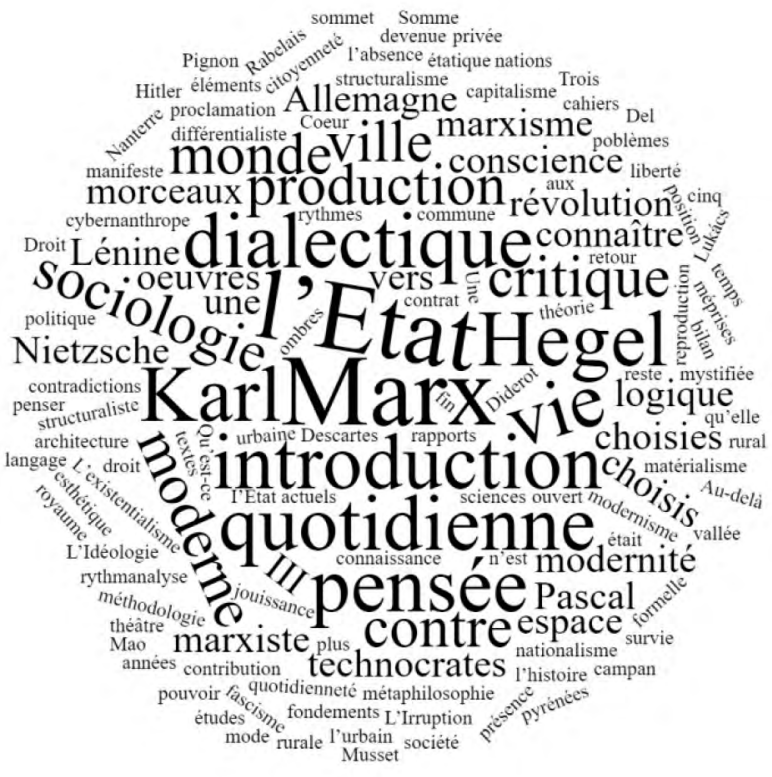

Fuente: Elaboración propia mediante una plataforma de nubes de palabras

NOTA: Se han empleado la bibliografía que cita Martínez (2012, pp. 11-12) y Lefebvre (2018, p. 49).

inducen a pensar que esas descripciones y esos recortes tan solo aportan inventarios de lo que existe en el espacio, o en el mejor de los casos dan lugar a un discurso sobre el espacio, pero nunca a un conocimiento del espacio (Lefebvre, 2013, p. 68).

El interés era de generar una teoría donde se relaciona las concepciones de la realidad sustraída de la razón mental, física y lo social en respuesta de la reducción y desintegración del conocimiento vinculado al método científico, por lo cual, desarrollaría una propuesta que engloba tres dimensiones que comprende:

En primer lugar, del físico, la naturaleza, el Cosmos; a continuación, del mental (incluida la abstracción formal y la lógica); y, por último, del social. 
En otros términos, la investigación concierne al espacio lógico-epistemológico, al espacio de la práctica social, al espacio ocupado por los fenómenos sensibles, sin excluir lo imaginario, los proyectos y proyecciones, los símbolos y las utopías (Lefebvre, 2013, p. 72).

Del planteamiento anterior podemos extraer tres ideas claves que relaciona a la teoría unitaria de la producción del espacio: en la primera responde a lo mental que después denominaría como representación del espacio que está constituido por la razón instrumental del saber científico donde predomina la cuestión geométrica del espacio por el predominio de métodos formales; segundo tiene que ver con las relaciones sociales de producción y reproducción; $y$, tercero lo que denomina como la cuestión física o naturaleza que comprende a las dimensiones simbolizadas que el ser humano tiene la capacidad de imaginar y de percibir en:

Nuestra relación con la naturaleza se transforma: ni amiga ni enemiga; ni aplastante ni favorable sino nuestro dominio y nuestro bien. El problema ya no es el del volver cósmico a lo humano. El problema se plantea y se resuelve en el plan humano y desde el punto de vista del hombre. El hombre no puede descubrir en la naturaleza sino lo que ha descubierto en sí mismo. Es pues, a través del hombre como naturaleza toma una significación (Lefebvre, 1975a, p. 139).

Esta guisa de dimensiones tiene como meta de "[...] mostrar la producción del espacio mediante la reunión en una teoría de los diversos tipos de espacios y las modalidades de su génesis" (Lefebvre, 2013, p. 77), ya que "el espacio social es un producto social" (Lefebvre, 2013, p. 86). Ahora bien, una de las preguntas importantes que nos hemos formulado: ¿Dónde proviene la tríada, en particular, la de la teoría unitaria de la producción del espacio?

La respuesta es compleja debido a las distintas posibilidades que podrían explicarse, pero, un punto de partida sería a través del apartado Las Tríadas que vienen en el libro de Hegel, Marx y Nietzsche (o el reino de las sombras) donde indica que: "estudiar a Hegel, Marx o Nietzsche aisladamente, en los textos, no sirve de mucho [...]" (Lefebvre,1976c, p. 5); de esta manera establece que el mundo moderno es Hegeliano debido que se "piensa en términos de Estado [...]" (Lefebvre, 1973a, p. 21) mientras "en Marx y para el marxismo sigue estando bastante claro: la 
razón nace de la práctica, del trabajo y de su organización, de la producción y de la reflexión inherente a la actividad creadora tomada en toda su amplitud" (Lefebvre, 1984b, p. 25); y, es nietzscheano porque se "piensa en términos de civilización" (Lefebvre, 1973a, p. 22) que dará el basamento sobre la cuestión del "vivir y lo vivido individuales se reafirman contra las presiones políticas, contra el productivismo y el economismo" (Lefebvre, 1976c, pp. 2-3).

Una tripleta de aportaciones bajo el respaldo de Marx, Hegel y Nietzsche, una anécdota curiosa referente a las dimensiones espaciales es la siguiente: "[...] yo había leído a Nietzsche y a Spinoza, es decir, que sin darme cuenta ya me iniciaba en la problemática de lo vivido y lo pensado" (Lefebvre, 1976b, p. 18) o bien, este último de lo concebido.

Ahora bien, descifrar la construcción de la primera dimensión espacial es complicado, ya que uno pudiera partir de las primeras traducciones que realizaría de Marx con el apoyo de su amigo Norbert Guterman que equivaldría a diseñar a la práctica espacial (Lefebvre y Guterman, 1970, pp. 9-378; 1974, pp. 8-367), en lo concerniente a la representación del espacio están aquellas publicaciones que tocan la lógica formal lógica dialéctica, contra los tecnócratas, los cuatro volúmenes del Estado e inclusive los que hablan sobre Hegel y los espacios de representación que se sitúan por su formación académica.

Otra alternativa de explicación es formulada por Christian Schmid al establecer que la teoría unitaria de la producción del espacio relaciona una "[...] dialéctica tridimensional que emergen tres momentos que están dialécticamente interconectados: práctica social (Marx); lenguaje y pensamiento (Hegel); y el acto creativo y poético (Nietzsche)" (2008, p. 33) que relacionadas explican la totalidad de "la materialidad de la práctica social (práctica espacial, representación del espacio y espacio de representación) y el papel central del cuerpo humano (lo percibido, lo concebido y lo vivido) (Schmid, 2008, p. 40, cursivas propias).

Aunque con el pensamiento triple de Lefebvre ya había dado cuenta de la imbricación de "la producción de productos (medios de producción, bienes de consumo, productos suntuarios), producción de relaciones sociales (reproducción biológica "familia") y producción de obras (objetos, instituciones e ideologías)” (Lefebvre, 1973b, pp. 203-204). 
Ahora bien, en lo concerniente a los espacios de representación una de las interpretaciones responde a la cuestión del símbolo, este concepto es polisémico y polivalente por las múltiples disciplinas ${ }^{4}$, por su parte, a lo correspondiente a Lefebvre nos situamos en su publicación La producción del espacio, al respecto, menciona lo siguiente de los espacios de representación: "que expresan (con o sin codificación) simbolismo complejos ligados al lado clandestino y subterráneo de la vida social, pero también al arte (que eventualmente podría definirse no como código de los espacios de representación" (Lefebvre, 2013, p. 92) a esta misma conceptualización añade que "se trata del espacio dominado, esto es, pasivamente experimentado, que la imaginación desea modificar y tomar. Recubre el espacio físico utilizando simbólicamente sus objetos" (Lefebvre, 2013, p. 98).

De lo anterior, se puede observar dos conceptualizaciones, la primera envuelve a la crítica de la vida cotidiana, y, la segunda comprende al ejercicio del poder que se expresa por un dominante y un dominado donde los espacios de representación se encuentran en constante tensión y confrontación. En lo concerniente al tema de lo "[...] simbólico tiene generalmente una relación con lo mágico. Un objeto tomado como símbolo de una realidad inaccesible (lejana o trascendental) posee los amplios supuestos de esta realidad. Por contacto e inmediatez, contigüidad, contaminación, participación cercana, los comunica" (Lefebvre, 2018, p. 197).

A esto mismo, Lefebvre (1967, pp. 189-192) propone una clasificación que se compone de cuatro postulados, la primera denominada símbolos constitutivos en donde se caracteriza a la naturaleza que comprende a la fauna, la flora, el relieve entre otros; el segundo responde a los símbolos en oposición, aunque con mayor dominio se encuentra las de índole binaria sería importante incorporar la concepción tríadica; el tercero comprende a los conjuntos simbólicos de una totalidad de elementos que se representan por su dominio; $y$, por último, los símbolos organizados corresponden a las especificidades del espacio que lo hacen único. Véase el cuadro 1.

4 Por mencionar algunos, el debate viene desde los psicoanalistas, la sociología, los arquetipos de Jung que después retomaría Gaston Bachelard, Georges Gurvitch, Durkheim, Leibniz, Wittgenstein entre otros, véase a Lefebvre (1967, pp. 84-88) para conocer sobre el tema del símbolo. 


\section{Cuadro 1. Los espacios de representación bajo el tema del símbolo}

\begin{tabular}{|c|c|c|}
\hline Clasificación & Descripción & Ejemplo \\
\hline $\begin{array}{c}\text { Símbolos } \\
\text { constitutivos }\end{array}$ & $\begin{array}{c}\text { Su inventario parece limitado para cada } \\
\text { cultura, cada civilización, cada sociedad. } \\
\text { Estos símbolos son poderosamente margi- } \\
\text { nales respecto de los signos. Tiene algo de } \\
\text { fascinante. Se recurre a ellos para decir lo } \\
\text { que no logran decir los signos sistematiza- } \\
\text { dos: lo instintivo. }\end{array}$ & $\begin{array}{c}\text { El león, símbolo de fuerza y } \\
\text { de valentía; el agua, símbolo } \\
\text { de la vida. }\end{array}$ \\
\hline $\begin{array}{c}\text { Símbolos en } \\
\text { oposición }\end{array}$ & $\begin{array}{c}\text { A estos mismos, la oposición no los de- } \\
\text { fine, sino que cada uno de los términos } \\
\text { puede ser llevado a lo absoluto. }\end{array}$ & $\begin{array}{c}\text { El Padre y la Madre, lo bueno } \\
\text { y lo malo }\end{array}$ \\
\hline $\begin{array}{c}\text { Conjuntos } \\
\text { simbólicos }\end{array}$ & $\begin{array}{c}\text { Corresponde a los elementos que ellos de- } \\
\text { rivan, cuando se separan del conjunto (por } \\
\text { un procedimiento de difiere de la metáfora } \\
\text { y de la metonimia). }\end{array}$ & $\begin{array}{c}\text { La realeza se simboliza: la } \\
\text { corona, el cetro, el trono, la } \\
\text { espada, los gustos del rey. Los } \\
\text { objetos simbólicos tienen una } \\
\text { relación con los atributos efec- } \\
\text { tivos del rey: origen heroico o } \\
\text { divino, fuerza, justicia, rique- } \\
\text { za, nobleza. }\end{array}$ \\
\hline $\begin{array}{c}\text { Símbolos } \\
\text { organizados }\end{array}$ & $\begin{array}{c}\text { Se vinculan con las significaciones, sin } \\
\text { confundirse con ellas. Son los símbolos } \\
\text { por medio de los cuales los grandes gru- } \\
\text { pos sociales (los pueblos y las naciones, } \\
\text { las clases y también los grupos religiosos } \\
\text { e ideológicos) indican pertinencia. Resu- } \\
\text { men o condensan un conjunto de rasgos } \\
\text { reales, y lo muestran hacia afuera. Estos } \\
\text { símbolos remiten a los orígenes de sus } \\
\text { propiedades. }\end{array}$ & $\begin{array}{c}\text { lares saben que la bandera } \\
\text { republicana resume la unidad } \\
\text { histórica de la nación, al unir } \\
\text { los colores de la realeza con el } \\
\text { azul y el rojo de París, con el } \\
\text { rojo de la revolución. }\end{array}$ \\
\hline En Francia todos los esco- \\
\hline
\end{tabular}

Fuente: Elaboración propia a partir de Lefebvre (1967, pp. 189-192)

A esto mismo podemos sugerir que "[...] los espacios de representación intervengan de forma diferente en la producción del espacio: según sus cualidades y propiedades, según las sociedades (modo de producción), según las épocas" (Lefebvre, 2013, p. 104) en virtud de que "toda sociedad produce su espacio [...]" (Lefebvre, 1976d, p. 40) ya que "[...] tanto en la ciudad de ayer como en la del futuro, no existe el espacio urbano, sino espacios urbanos [...]" (Lefebvre, 1976a, p. 211) que caracterizan sus propios espacios de representación. 
Enrique de Jesús Castro-Martínez Aportes teóricos para la conceptualización de los espacios de representación de Henri Lefebvre

\section{Aportes teóricos para la conceptualización de los espacios de re- presentación bajo tres interpretaciones}

\section{a. Espacio simbolizado}

Una de las primeras conceptualizaciones que atañe a los espacios de representación obedece al "[...] espacio físico (definido por lo prácticosensible y la percepción de la naturaleza [...]" (Lefebvre, 2013, p. 87) a estas primeras proposiciones corresponden a tres tipos de escalas simbólicas, la primera responde al subsuelo como es la geomorfología submarina, por ejemplo: las dolinas; en la segunda se encuentra la escala del suelo que responde a consagración de la flora y la fauna, y, por último, está el sobre-suelo que responde a la valorización cosmológica como serían las estrellas, el sol, la luna, etc.

De estos antiguos espacios de representación, "el espacio natural fue muy pronto poblado por fuerzas políticas" (Lefebvre, 2013, p. 106) que pasaría a nombrarse como el "[...] espacio absoluto (religioso y político) se compone de lugares sagrados o malditos: templos, palacios, monumentos conmemorativos y funerarios, lugares privilegiados y distinguidos" (Lefebvre, 2013, p. 281). Por ejemplo, la arquitectura se apropió de los símbolos de la naturaleza dotándolos de un poder político, a esto mismo:

La arquitectura política incluye la arquitectura militar como la arquitectura religiosa incluye a la arquitectura de la contemplación. Fortalezas, palacios y castillos van juntos. El poder siempre intenta presentarse y representarse en lo eterno, a través de símbolos y obras arquitectónicas imperecederas. El poder se ejerce sobre un espacio que domina y protege; en él planta sus símbolos y sus instrumentos, siendo estos inseparables. El torreón tiene una doble relación, simbólica y práctica, con la tierra circundante que domina y penetra. Vigila el espacio, posee la naturaleza como un guerrero posee a la mujer conquistada y retenida, en parte por violencia, en parte por protección (Lefebvre, 2018, p. 68).

A estos conjuntos simbólicos de poder ejercen su dominio mediante la organización de la morfología de la ciudad por medio del control y de la apropiación del contenido del espacio como lo expresa los tipos del uso de suelo, aunque, del propio espacio en su totalidad. A esto mismo, la arquitectura religiosa son espacios simbolizados, en ellas "tienen una existencia simbólica más que funcional o estructural; lo que simboliza tiene su sede y 
su sentido más allá; es la religión, la iglesia católica y romana" (Lefebvre, 1976a, p. 199) que se manifiesta en distintas escalas constructivas como son los templos y monasterios entre otras más.

Los espacios simbolizados han cambiado a lo largo de la historia, un ejemplo particular se daría en la "[...] ciudad occidental, desde la ciudad renacentista italiana hasta la ciudad del siglo XIX [...]" donde la "[ $[.$.$] re-$ presentación del espacio dominó y subordinó al espacio de representación (de origen religioso) que era reducido a figuras simbólicas, el Cielo y el Infierno, el demonio y los ángeles" (Lefebvre, 2013, p. 99).

Estas mutaciones simbólicas que responden al monumento "a lo largo del siglo XIX, el Edificio destronó al Monumento" (Lefebvre, 2018, p. 72) promoviendo distinciones donde "el monumento se caracteriza por la búsqueda o la pretensión estética, por el carácter oficial o público, por la influencia que ejerce a su alrededor; mientras que el Edificio se define por la función privada, por la preocupación técnica, por la localización de un área prevista" (Lefebvre, 2018, p. 72) que sea promotora de símbolos para su consumo. Lo que podemos apreciar es que la concentración y expansión del capital se ha imbricado en la construcción de espacios simbolizados como es la naturaleza y después la arquitectura para transitar a su mercantilización.

Un cuestionamiento imprescindible que daría Lefebvre corresponde a la destrucción de los espacios que simbolizan a la naturaleza, pero también comprenden a los monumentos arquitectónicos, a esto mismo escribe que:

La primera de ellas es que el espacio-naturaleza desaparece irreversiblemente. Ciertamente el espacio natural fue y sigue siendo en parte el punto común de partida, el origen y el modelo original del proceso social, quizá la base de toda originalidad. Por supuesto que no desaparece pura y simplemente de la escena. Es aún el fondo del cuadro; como decorado, y más como ambientación, persiste por doquier y cada detalle, cada objeto natural se valora convirtiéndose en símbolo (el animal más insignificante, los árboles, la hierba, etc.) (Lefebvre, 2013, p. 90).

De la evocación anterior, se explica por dos partes, por un lado, se encuentra la asociación del Estado con el capital para promover la destrucción de los antiguos espacios simbolizados, por otro lado, a esa destrucción se asocia con una creación de simulacros o repeticiones de viejas 
arquitecturas que se mezclan en la actualidad. A todo esto, se promueve la resistencia simbólica y los contra-espacios ante la expansión del ejercicio de poder de Estado y la del capital en las ciudades.

b. Los símbolos del capital en la sociedad burocrática del consumo dirigido

La cotidianidad ha tenido cambios importantes a lo largo de la historia, aunque Lefebvre postula que: “[...] hasta el siglo XIX, hasta el capitalismo concurrencial y hasta el desarrollo del mundo de la mercancía, no existía el reino de la cotidianidad" (Lefebvre, 1984b, p. 52), esto se debe en gran parte a que el capital cada vez se ha ido incorporando en nuestros aspectos sociales, culturales y espaciales. A ello, Henri Lefebvre se había percatado de este proceso al escribir:

El espacio social contiene y más o menos asigna los lugares apropiados a: (1) las relaciones sociales de reproducción a saber, las relaciones biofisiológicas entre los sexos, las edades, con la especifica organización familiar; (2) las relaciones de producción i.e. a la división del trabajo y su organización, y por tanto a las funciones sociales jerarquizadas. Estos dos conjuntos de relaciones, producción y reproducción no pueden separarse: la división del trabajo repercute en la familia y la sostiene; inversamente, la organización familiar interfiere en la división del trabajo (Lefebvre, 2013, p. 91).

Una de las ideas que sustraemos de la cita anterior, es que el capital permea al interior y exterior de los espacios de representación, es decir, interioriza hasta la escala del ser humano como consecuencia de alienación de la lógica del capital, a esto mismo responde desde el comportamiento hasta llegar a las entrañas del cuerpo en las maneras en que consumimos en y del espacio urbano, en un sentido similar Lefebvre escribiría lo siguiente: "[...] al capitalismo que ha impulsado la división del trabajo hasta el interior del cuerpo de los trabajadores e incluso de los no trabajadores" (Lefebvre, 2013, p. 248), por un lado, pero, también el capital se ha incorporado en la construcción de símbolos de poder de comercialización y mercantilización estimulando su apropiación y dominación, por el otro lado.

Bajo la idea anterior, Lefebvre propone tres etapas que resumen los tres primeros volúmenes de la Crítica de la vida cotidiana, que vienen en su publicación La vida cotidiana en el mundo moderno, aunque es un ejercicio realizado en Francia, consideramos pertinente que contiene 
elementos que podrían ser similares a otros países, aunque con sus propias especificidades.

En la primera etapa realiza una crítica a la cotidianidad diciendo que "la obra casi ha desaparecido, sustituida por el producto (comercializado), mientras que la explotación ha reemplazado a la opresión violenta" (Lefebvre, 1984b, p. 52). Esto se debe a la modernidad que ha contribuido al "ascenso de las masas (que no impide su explotación), la democracia (idéntica observación), significan el fin de los grandes estilos, de los símbolos y de los mitos, de las obras colectivas: monumentos y fiestas" (Lefebvre, 1984b, p. 53).

En la segunda etapa se enmarca bajo el periodo de posguerras donde prevalece una fuerte intervención del Estado que prevaleció durante el modelo de desarrollo industrial que impulsaría a la par el proceso de urbanización. El dominio que se promovió fue por la tecnocracia en la planeación de las ciudades que respondía a una cuestión indicativa o racional que se expandió a lo cotidiano de la sociedad. Los espacios de representación no fueran inmunes ante esta concentración y expansión de la técnica en lo cotidiano por el ascenso del capital, ya que:

Durante un primer periodo parecía indicado mostrar la riqueza de lo cotidiano (cf. El t. I de la Crítica de la vida cotidiana, publicado poco después de la Liberación). Pero pronto la penetración del capitalismo en lo cotidiano y su integración provocaron el empobrecimiento, la trivialidad. En lo cotidiano se desplegaba el mundo de la mercancía, que ocupaba el tiempo y el espacio, sin brutalidad aparente, gracias a una analogía en el intercambio entre mercancía y lenguaje (cf. El t. II de la Crítica de la vida cotidiana, 1961). Ese mundo de la mercancía utilizaba las ciencias sociales y sobre las técnicas manipuladoras y programadas de lo cotidiano: publicidad, referencias directas e indirectas. Producía las necesidades con la apariencia de producir tan sólo objetos para las necesidades de los "consumidores" (Lefebvre, 2006, p. 224).

La interiorización del capital en la vida cotidiana se define a que “ hoy todo el espacio entra en la producción como un producto en función de su compra, venta e intercambio de las partes del espacio" (Lefebvre, 1976e, p. 160), los espacios de representación no son ajenos a esta dinámica, ya que en la ciudad actual se "[...] completa con un consumo en lo imaginario y de lo imaginario, desdoblando también él: consumo de 
imágenes (cine, televisión, reproducciones) y consumo de signos" (Lefebvre, 1972a, p. 29), lo que se promueve es "la eliminación de los símbolos y simbolismo en provecho de los signos y, después, de las señales" (Lefebvre, 1984b, p. 54).

En la urbanización planetaria "[...] se producen signos y significaciones para venderlos, para consumirlos (por ejemplo, la retórica publicitaria del agente inmobiliario)" (Lefebvre, 1976e, p. 58) que responden a "la producción de estos signos se integra en la producción global y desempeña un papel integrador capital en relación a las otras actividades sociales productoras u organizadoras" (Lefebvre, 1978, p. 82), lo que ha sucedido es que los símbolos ya no se producen ahora han pasado a producir signos como representaciones que "se los fabrica para ser concebidos en el plano de lo visible: visibilidad de gentes y cosas, de espacios y de todo aquello que éstos contengan" (Lefebvre, 2013, p. 132).

Por esto mismo, "hubo un tiempo de símbolos, de particularidades naturales y sustanciales. Después, su negación: el mundo de los signos, formal, abstracto, igual en todos lados [...]" (Lefebvre, 1975b, p. 133) en respuesta a la homogeneidad que tiende a la repetición, a la simulación y a los simulacros.

A esto se añade que la propia naturaleza ${ }^{5}$ se compra y se vende como un gran negocio que se representa en lo inmobiliario, edificios que intentan lograr licencias verdes que son patrocinadas por transnacionales, la naturaleza se convierte en un símbolo del negocio, Lefebvre da cuenta de esto mismo:

Dichos símbolos se producen masivamente y se venden. Un árbol, una flor, una rama, un perfume, una palabra se convierte en símbolos de la naturaleza ausente, se convierten en su presencia ficticia e ilusoria. Al mismo tiempo, la naturalización ideológica se hace obsesiva. En toda publicidad, ya sea de productos alimenticios o textiles, ya sea de viviendas o de vacaciones, la referencia a la naturaleza es constante. Todos los "significados flotantes" que utiliza la retórica se aferran a su re-presentación con el fin de darles sentido y contenido. Aquello que ya carece de sentido pretende volver a hallarlo utilizando el fetiche "naturaleza" (Lefebvre-1976e, pp. 33-34).

5 La segunda naturaleza, distanciada de la naturaleza original pero concreta a su nivel, se habría emancipado de la artificialidad y sin embargo ya no tendría nada de natural (Lefebvre, 2013, p. 408). Para conocer más sobre el tema de la conquista de la naturaleza, véase a Lefebvre (1971, pp. 124-145). 
En respuesta a la compra-venta de todos estos espacios simbolizados se han orientado a la sociedad burocrática de consumo dirigido que está gestando la sociedad urbana (Lefebvre, 1976e, p. 10), pero sobre todo a las distintas modalidades que adoptan los espacios de representación que se vuelven registros de mercantilización mediante las estrategias de venta del marketing urbano y la creación de eslóganes impulsados por la marca de la ciudad.

Así, "nuestra sociedad (llamada de consumo, o de abundancia, o técnica) es ante todo terrorista. El terrorismo está en todas partes: en el menor detalle de lo cotidiano y en la alta cultura y la literatura altamente calificadas" (Lefebvre, 1972a, p. 135), ese terrorismo se ha imbricado a cualquier tipo de escala espacial que obedece a la "sociedad burocrática de consumo dirigido"6 (Lefebvre, 1984b p. 79) cuyo marco teórico se sitúa en la interiorización del capitalismo en asociación con la política del Estado que controla y domina a la cotidianidad, aunque, la estrategia es más grave debido a las palabras que se emplean, "[...] la sociedad de consumo ocultan el hecho de que grupos enteros están excluidos del consumo (y que otros llegan a un sobreconsumo de productos inútiles, sin contar con el derroche organizado)" (Lefebvre, 1967, p. 121).

En la tercera etapa es la fase superior de la sociedad burocrática de consumo dirigido que responde a la alineación de las nuevas tecnologías y medios de comunicación y, que generan la "cibernetización" (Lefebvre, 1984b, p. 84) donde el ser humano se volvería dependiente de la era del cibernantropo y del robot (Lefebvre, 1972a, pp. 165-175).

\section{c. Del espacio diferencial al contra espacio}

En el desarrollo del capitalismo se ha promovido múltiples producciones de espacios con múltiples contradicciones que "[...] envuelven las contradicciones históricas, las supone y superpone, las empuja a un grado superior, y las amplía mientras las reproduce" (Lefebvre, 2013, p. 368) permitiendo que en "la producción del espacio no puede producir más que espacio diferencial"” (Lefebvre, 1976d, p. 126). Estos espacios

6 Para concretizar a ese tipo de sociedad, se tiene que regresar para analizar la sociedad industrial, sociedad tecnocrática-burocrática, sociedad de abundancia, sociedad del ocio y la sociedad de consumo (Lefebvre, 1984b, pp. 62-79).

7 Para ampliar el tema de la diferencia, véase a Lefebvre (1975b), aunque tomando en consideración que en dicho libro se aplica el método regresivo-progresivo propuesto por Lefebvre. 
diferenciados, "las diferencias que se manifiestan y se instauran en el espacio no provienen del espacio como tal, sino de lo que en él se instala, se reúne y se confronta por/en la realidad urbana" (Lefebvre, 1976e, p. 131).

A este espacio diferencial responde, por un lado, a la "[...] posición muy pertinente entre los espacios dominados y los espacios apropiados" (Lefebvre, 2013, p. 212), y se relacionan por un grupo de tríadas que se denominan como las topías (iso-hetero-u-topía) (Lefebvre, 1976e, p. 137), por el otro lado. En las isotopías responden a los "lugares de lo idéntico, idénticos lugares. Orden próximo. Mientras que las heterotopías comprenden al otro lugar y el lugar de lo otro, excluido e implicado a la vez" (Lefebvre, 1976e, p. 134), y, por último, "las utopías (espacios ocupados por lo simbólico y lo imaginario: por idealidades tales como la naturaleza, el saber absoluto y el poder absoluto)" (Lefebvre, 2013, p. 398).

Las isotopías se entienden como la homogeneidad que promueve diferencias. "Lo diferente es en primer término lo excluido: las periferias, las barriadas de chabolas, los espacios de juegos prohibidos, de las guerras y de las guerrillas" (Lefebvre, 2013, p. 405). En las ciudades se representan por las heterotopías, que "a menudo, cortes/suturas (por ejemplo, la calle ancha o la avenida que separa y/o reúne dos barrios, dos heterotopías contrastantes) (Lefebvre, 1976e, p. 134). Pero, en las ciudades de hoy en día no sólo hay un espacio, “[...] tanto en la ciudad de ayer como en la del futuro, no existe el espacio urbano, sino espacios urbanos, varios espacios diferenciados [...]" (Lefebvre, 1976a, p. 211) que son lugares que ha dominado la lógica de acumulación del capital flexible a través de la proliferación de discursos neoliberales que han beneficiado a grandes grupos capitalistas para la compra-venta de ciertos fragmentos selectivos.

Un ejemplo central es la distinción de la isotopía en relación con las heterotopías que se vendría a estar configurada desde siglos atrás, Lefebvre da cuenta de esto mismo:

Comparado con el espacio rural, el espacio urbano tuvo un carácter heterotópico hasta el cambio que empieza en Europa en el siglo XVI y termina con la invasión del campo por el tejido urbano. Durante esta época, los arrabales conservaron un carácter muy notable de heterotopía: poblaciones de orígenes diversos, carreteros y viajeros, auxiliares de comercio, seminómadas obligados a establecerse fuera de los recintos, población sospechosa, sacrificada en caso de la guerra; largas vías del mal dotadas, espacios 
ambiguos. Pero, poco a poco, la ciudad absorbe estos arrabales, los asimila y los añade a sus barrios activos, los de los comerciantes y artesanos. Así se fue formando la aglomeración urbana, poderosa unidad popular, cimentada por las luchas contra el estado monárquico. Solo al llegar la época burguesa pudo nacer el movimiento contrario: la expulsión de los elementos populares del centro hacia las hererotopías periféricas aún rurales, convertidas desde entonces en "afueras", receptáculos de la zona habitación y dotadas de una isotopía particularmente legible (Lefebvre, 1976e, pp. 134-135).

El epígrafe CONTRA es un silogismo presente en las discusiones de los escritos de Lefebvre, por ejemplo, en la producción del espacio del capital potencializa "las contradicciones del espacio" (Lefebvre, 1976d, p. 30) que promueve al "espacio diferencial” (Lefebvre, 2013, p. 385), para analizar la representación del espacio por medio del dominio de la técnica en la vida cotidiana aparece el libro titulado: Contra los tecnócratas (1972a, pp. 13-182), mientras que para analizar algunos postulados que comprenden a los espacios de representación lo hace en el subapartado denominado: Contra el antiguo romanticismo (2012) e inclusive para combatir al terrorismo se sitúa para oponerse por el "contraterrorismo" (Lefebvre, 1984b, p. 230), a esto responde al pensamiento dialectico, que algunos han denominado como la "dialéctica tridimensional" (Schmid, 2008, p. 33) o "dialéctica de triplicidad" (Soja, 2010, p. 193).

Así pues, el contra-espacio consiste "cuando una población se opone a un programa de construcción de carreteras o de extensión urbana, cuando la población reclama equipamientos o plazas libres para el juego y el encuentro social [...] (Lefebvre, 2013, p. 413) y, cuando la población resiste la demolición de sus símbolos producidos.

El contra-espacio es una respuesta de "la sociedad represiva" por una práctica del capital o una representación instrumental promovida por el Estado (Lefebvre, 1984b, p. 178), donde el beneficio responde a grandes grupos de empresarios que producen su propio espacio, es el espacio de la mercantilización, comercialización y privatización.

A estos factores, el pensamiento de Lefebvre apostaría a tener una visión de la virtualidad que se refiere a lo posible para contrarrestar los antagonismos y las contradicciones que aquejan a la sociedad. Aunque el juego de topias aparece la u-topia que es el "ahora presente, virtualidad aclaradora, absorbería y metamorfosearía las topías” (Lefebvre, 1976e, p. 
137), esa virtualidad entendida como posibilidad “está en todas partes y no está en ninguna" (Lefebvre, 1976e, p. 137).

Si bien el espacio del capital entendido desde la teoría unitaria del espacio que engloba a las prácticas del espacio, representación del espacio y el espacio de representación, a este último se promueve el contraespacio, esto porque "el espacio del usuario es vivido, no representado (o concebido) [...] el espacio de las actividades cotidianas de los usuarios es un espacio concreto. Lo que quiere decir subjetivo" (Lefebvre, 2013, p. 395), por esto mismo, es el espacio de la lucha social, de las revoluciones urbanas, del Derecho a la Ciudad y de la autogestión.

Así pues, en el contra-espacio son el resultado de las heterotopías, pero también son:

Los campos ciegos se producen entre los campos, los cuales, lejos de ser apacibles, son campos de guerra y de conflictos. No se trata únicamente de campos oscuros, inciertos y mal explorados, sino que son ciegos de igual forma que existe en la retina un punto ciego, centro de la visión, y, sin embargo, su propia negación. Paradojas. El ojo no se ve, tiene que recurrir a un espejo. El punto central de la visión no se ve y no sabe que está ciego (Lefebvre, 1976e, p. 35).

Los campos ciegos son a la vez mentales y sociales, los primeros se relacionan con la óptica de la representación espacial que viene diseñada por discursos ideológicos, la segunda es la base operacional que vincula a la anterior. Ese campo ciego que pretenden ocultar de las heterotopías es promovido por dos lecturas, la primera es la imagen al exterior dentro de la cual no sucede nada para seguir promoviendo a la metrópoli por estrategias como el marketing urbano y la marca de la ciudad, pero, la otra imagen que responde al interior de las metrópolis es la del contra-espacio como resultado de los grandes desarrollos financieros e inmobiliarios.

En donde los más desfavorecidos en respuesta al agotamiento de los espacios de representación tienden a concretizar la resistencia que impulsaría las prácticas y las representaciones del espacio por el bien común. Así pues, y "en realidad, para cambiar la vida es preciso cambiar el espacio" (Lefebvre, 2013, p. 236) a través de espacios alternativos que puedan impulsar "[...] contra-planes y contra-proyectos que frustren las estrategias, los planes y los programas impuestos desde arriba" (Lefebvre, 2013, p. 
414) como un mecanismo del "contra-espacio" (Lefebvre, 2013, p. 415) que daría paso a la "[...] revolución del espacio (que incluye, pues, la revolución urbana ${ }^{8}$ ) [...]" (Lefebvre, 2013, p. 448) que brindará elementos para la resistencia urbana por medio del derecho a la Ciudad (Lefebvre, 1978, pp. 138-139) o la autogestión como "[...] vía de una transformación de la vida cotidiana; el sentido del proceso revolucionario se define así: cambiar la vida" (Lefebvre, 1974, p. 92) como fue la experiencia de:

La comuna representa hasta nosotros la única tentativa de un urbanismo revolucionario, atacando sobre el terreno los signos petrificados de la vieja organización, captando las fuentes de la sociabilidad -en ese momento el barrio- reconociendo el espacio social en términos políticos y no creyendo que un monumento pueda ser inocente (demolición de la columna Vendôme, ocupación de las iglesias por los clubes, etc.) (Lefebvre, 1972b, p. 53).

Esta experiencia para transformar el antiguo casco urbano para el beneficio de la cotidianidad de la clase obrera que potencializa la destrucción de los espacios de representación creados por las estrategias e instrumentos del Estado, dan cuenta de la materialización del Derecho a la Ciudad que reclama la ciudadanía. Aunque, este Derecho a la Ciudad conceptualizado desde los espacios de representación, responde a lo social que promueve las prácticas espaciales y la representación del espacio como proceso de cambio radical del espacio urbano.

\section{Conclusiones}

El pensamiento de Henri Lefebvre contribuye a elucidar una amplitud de conceptualizaciones en sus postulaciones, esto es debido al enfoque heterodoxo y al método que emplea, además del dialéctico aparece el de la transducción que responde a la posibilidad. Por ello, los espacios de representación como una dimensión espacial de la teoría unitaria de la producción del espacio tienen las mismas especificidades de interpretación por su carácter polisémico, polivalente y de la virtualidad.

Un punto central que relaciona a los espacios de representación es el factor histórico, que en cada momento define sus propios significados y en cada espacio que se produce dotará sus propias propiedades, a esto

8 La revolución en el pensamiento de Lefebvre la concibe como total a través de tres niveles: nivel económico, nivel político y nivel cultural (1984b, pp. 238-239). 
mismo, es imprescindible que en la construcción de los espacios de representación se incorpore el método regresivo-progresivo de Henri Lefebvre.

Por otro lado, en lo tocante al símbolo responde a múltiples interpretaciones de los espacios de representación y, que a lo largo de la historia ha mutado por el dominio de la técnica y la apropiación del capital para su venta y compra. Se construyen símbolos como meras repeticiones a escala de la urbanización planetaria volviendo a los espacios urbanos homogéneos, fragmentados y jerarquizados.

A esto mismo, la expansión del capital en asociación con el Estado ha estimulado la destrucción de los símbolos producidos por la sociedad por la creación de simulacros y de signos. Esto ha promovido una chispa que detona al contra-espacio donde la resistencia urbana y la lucha social del espacio germine en la revolución urbana tomando como insignia de batalla la siguiente frase: "EL DERECHO A LA CIUDAD".

\section{Referencias}

Hess, R. y Weigand, G. (2006). Henri Lefebvre et son oeuvre. Disponible en: http://www.barbier-rd.nom.fr/H.\%20Lefebvre.pdf.

Lefebvre, H. (1967). Lenguaje y sociedad. Argentina: PROTEO.

Lefebvre, H. (1971). Introducción a la modernidad. Madrid: Tecnos.

Lefebvre, H. (1972a). Contra los tecnócratas. Argentina: granica editor.

Lefebvre, H. (1972b). La significación de la comuna. En: Lefebvre y otros. La crisis actual de la política. Argentina: Rodolfo Alonso Editor.

Lefebvre, H. (1973a). La violencia y el fin de la historia. Argentina: Ediciones siglo veinte.

Lefebvre, H. (1973b). Estructuralismo y política. Buenos Aires: Editorial La Pleyade.

Lefebvre, H. (1974). La revolución de hoy. México: extemporáneos.

Lefebvre, H. (1975a). Nietzsche. México: Fondo de Cultura Económica.

Lefebvre, H. (1975b). Manifiesto diferencialista. México: siglo veintiuno.

Lefebvre, H. (1976a). De lo rural a lo urbano. Argentina: Lotus mare.

Lefebvre, H. (1976b). Tiempos equívocos. España: Kairós.

Lefebvre, H. (1976c). Hegel, Marx, Nietzsche (o el reino de las sombras). México: siglo veintiuno editores.

Lefebvre, H. (1976d). Espacio y política. El derecho a la ciudad II. Barcelona: ediciones península. 
Lefebvre, H. (1976e). La revolución urbana. España: Alianza editorial.

Lefebvre, H. (1978). El derecho a la ciudad. Barcelona: Ediciones Península.

Lefebvre, H. (1980a). Introducción. En: Lefebvre, H. (dirección). Actualidad de Fourier. Venezuela: Monte Ávila editores.

Lefebvre, H. (1980b). Lógica formal lógica dialéctica. México: siglo veintiuno editores.

Lefebvre, H. (1984a). El existencialismo. Rosario: Documentos.

Lefebvre, H. (1984b). La vida cotidiana en el mundo moderno. España: Alianza editorial.

Lefebvre, H. (2006). La presencia y la ausencia. Contribución a la teoría de las representaciones. México: Fondo de Cultura Económica.

Lefebvre, H. (2007). Ritmo-análisis. Espacio, tiempo y vida cotidiana. Nueva York-London: Continuum.

Lefebvre, H. (2012). Hacia un romanticismo revolucionario. Buenos Aires: Ediciones Nueva Visión.

Lefebvre, H. (2013). La producción del espacio. España: Capitán Swing.

Lefebvre, H. (2018). Hacia una arquitectura del placer. España: Centro de Investigaciones Sociológicas.

Lefebvre, H. y Guterman, N. (1970). Karl Marx, oeuvres choisies 2. France: idées nrf.

Lefebvre, H. y Guterman, N. (1974). Karl Marx, oeuvres choisies 1. France: idées/gallimard.

Lencioni, S. (2015). Totalidad y tríadas: comprendiendo el pensamiento de Lefebvre. En: de Mattos, C. y Link, F. (eds.). Lefebvre revisitado: capitalismo, vida cotidiana y el derecho a la ciudad. Chile: RIL editores.

Martínez, E. (2012). Breve biografía y bibliografía de Henri Lefebvre. Revista URBAN, NS 02, pp. 7-13. Disponible en: http://polired.upm.es/ index.php/urban/article/view/1481/1488

Schmid, C. (2008). Henri Lefebvre's theory of the production of space. Toward a three-dimensional dialectic. En: Goodnewardena, k., Kipfer, S., Milgrom, R. and Schmid, C. (Edited). Space, Difference, Everyday Life. Reading Henri Lefebvre. New York: Routledge Taylor and Francis Group. 
Soja, E. (2010). Tercer espacio: extendiendo el alcance de la imaginación geográfica. En: Benach, N. y Albet, A. (Orgs.). Edward W. Soja. La perspectiva postmoderna de un geógrafo radical. España: Icariaespacios críticos. 